\title{
ENDOPROSTHETIC REPLACEMENT OF THE PROXIMAL HUMERUS
}

\author{
A. C. ROSS, J. N. WILSON, J. T. SCALES \\ From the Institute of Orthopaedics (University of London) and the Royal National Orthopaedic Hospital, \\ Stanmore
}

\begin{abstract}
Endoprosthetic replacement of the proximal humerus has been performed in our unit on 25 occasions between 1950 and 1982. The indication for surgery was destruction of the proximal half of the humerus so extensive that the only alternatives were reconstruction or amputation.

Of the patients with tumours two died from metastases, and three from unrelated causes; local recurrence necessitated amputation in two patients. Minor complications were frequent, but there were no deep infections and, after 1964, no prosthesis became loose. Active shoulder movement after operation was considerably limited, but passive movement was good and function of the elbow and hand were preserved.
\end{abstract}

The proximal part of the humerus is a common site for tumours which, by destroying bone, render the upper arm unstable and prevent useful hand function. If a tumour can be resected, it is clearly undesirable and unnecessary to amputate an otherwise normal arm. The alternatives are to leave the patient with a flail arm and poor function, or to reconstruct or replace the area of bone loss.

Reconstruction may be carried out using autografts or cadaveric allografts. Avascular fibular autografts have been used for many years (Rovsing 1910; Albee 1921; Schauffler 1926; Clark 1959; Lettin 1964; Wilson and Lance 1965) and act as a passive spacer without attempting to recreate the shape or function of a normal humeral head. They tend, however, to fracture if longer than $12 \mathrm{~cm}$ and the fracture may not unite (Enneking, Eady and Burchardt 1980). Enneking (1983) has used paired fibular autografts both as an articulating spacer and also incorporated in a resection arthrodesis. Avascular autografts have also been used in conjuction with Neer prostheses to reconstruct defects in the humeral head and shaft (Smith and Simon 1975; Imbriglia, Neer and Dick 1978).

Vascularised fibular autografts have been used

A. C. Ross, MB, FRCS, Senior Orthopaedic Registrar St Mary's Hospital, Praed Street, London W2 INY, England.

J. N. Wilson, FRCS, Consultant Orthopaedic Surgeon

J. T. Scales, OBE, FRCS, CIMechE, Professor of Biomedical Engineering

Royal National Orthopaedic Hospital, Brockley Hill, Stanmore, Middlesex HA7 4LP, England.

Requests for reprints should be sent to Mr A. C. Ross.

(C) 1987 British Editorial Society of Bone and Joint Surgery 0301-620X/87/4131 \$2.00 occasionally and are recommended for defects greater than $6 \mathrm{~cm}$ when used singly (Weiland, Moore and Daniel 1983), or for defects greater than $12 \mathrm{~cm}$ when used to supplement an avascular graft (Enneking 1983).

Allografting, using freeze-dried cadaveric bone, has been undertaken in a number of centres (Volkov 1970; Ottolenghi 1972; Parrish 1973; Mankin, Doppelt and Tomford 1983; Gross et al. 1984), but considerable facilities and expertise are required to maintain an adequate bone bank (Doppelt et al. 1981). The application of this technique to the humerus has presented particular problems: Parrish (1973) reported fracture of the graft in two of his three cases, and Mankin (1983) found the highest incidence of graft fractures $(36 \%)$ and of non-unions $(28 \%)$ when allografting the humerus. In fact $50 \%$ of all graft fractures and $44 \%$ of non-unions occurred when replacing the humerus. Fresh vascularised allografts and xenografts do not, at present, seem to provide an alternative since there are immunological problems.

Prosthetic replacement of the upper humerus was first described by Péan in 1894 (Péan 1894; Lugli 1978). Since then there have been isolated case reports (Poirier 1968; Milgram and Riley 1972; Packard 1973; Yoshimoto, Kaneso and Tatematsu 1977) and, more recently, reviews of two larger series (Campanacci et al. 1975, 1982; Salzer et al. 1979). The first endoprosthetic (or massive) humeral replacement, substituting both the humeral head and a segment of the upper humeral diaphysis, was implanted at the Royal National Orthopaedic Hospital in 1950 (Burrows, Wilson and Scales 1975), and between that year and 1982, 25 prostheses were implanted in 24 patients whose results are reported here. 
Table I. Diagnosis and number of lesions requiring endoprosthetic replacement of the proximal humerus

\begin{tabular}{|c|c|}
\hline Diagnodis & Number \\
\hline $\begin{array}{l}\text { Non-malignant (6) } \\
\text { Enchondroma } \\
\text { Osteomyelitis } \\
\text { Rheumatoid arthritis } \\
\text { Massive osteolysis } \\
\text { Failed massive replacement* } \\
\text { Failed total replacement }\end{array}$ & $\begin{array}{l}1 \\
1 \\
1 \\
1 \\
1 \\
1\end{array}$ \\
\hline $\begin{array}{c}\text { Low-grade malignancy (16) } \\
\text { Chondrosarcoma } \\
\text { Parosteal sarcoma } \\
\text { Giant-cell tumour } \\
\text { Unspecified tumour }\end{array}$ & $\begin{array}{l}7 \\
4 \\
4 \\
1\end{array}$ \\
\hline $\begin{array}{l}\text { High-grade malignancy }(3) \\
\text { Secondary hypernephroma } \\
\text { Malignant round-cell tumour }\end{array}$ & $\begin{array}{l}2 \\
1\end{array}$ \\
\hline Total & 25 \\
\hline
\end{tabular}

- See text

\section{PATIENTS AND METHOD}

A retrospective study of 24 patients who had had a prosthetic proximal humeral replacement at the Royal National Orthopaedic Hospital between May 1950 and September 1982 was carried out (one prosthesis was revised, giving a total of 25 procedures). All the prostheses were designed and made in the Department of Biomedical Engineering of the Institute of Orthopaedics, Stanmore. The chosen date for the end of the period of follow-up was 30th September 1983, by which time five patients had died and six were living abroad but were reviewed regularly by their local doctors who kept us informed of their progress. The remainder were seen in person by at least one of the authors, and their notes and radiographs were reviewed.

Fourteen patients were female and 10 male, with an age range of 16 to 61 years. Fifteen of the lesions were in the right humerus, nine in the left. The diseases for which the replacements were undertaken are shown in Table I. Design of prosthesis. Between 1950 and 1955 lowmolecular-weight polyethylene (Alkathene) prostheses (Imperial Chemical Industries, UK) were implanted in four patients and fixed to the distal humerus with plates and screws (Figs 1 to 3 ). The plates were initially made of stainless steel but afterwards from a cobalt-chromemolybdenum alloy (Vinertia; Deloro Stellite Ltd, UK). All failed because the screws pulled out of the bone; this occurred because of avascular necrosis of the humeral remnant after extensive interruption of its blood supply by periosteal elevation and transection (Burrows et al. 1975). One prosthesis fractured.

The fifth implant (1963) was made of Titanium 160 (T1-5; IMI Titanium Ltd, UK) and was used to revise a loose polyethylene prosthesis. Because the patient's humeral remnant was so small, the prosthesis was fitted with divergent "fishtail" prongs (Figs 4 to 6). It remains functionally sound after 21 years. A second prosthesis of this design loosened but is not painful and has not therefore been revised. The next three patients (1964 to 1971) were fitted with prostheses which were handturned from Titanium 160; these implants had a cemented intramedullary stem and were linked by bolts or rivets.

In 1972, hoping to improve the function and wear of the prosthesis, three attempts were made to insert a total shoulder replacement rather than a hemiarthroplasty. These were unsuccessful because the prosthesis was too bulky, the cup too difficult to fix securely and the resulting articulation too unstable. In each case a riveted Titanium 318 (TA1; IMI Titanium Ltd, UK) humeral component with an intramedullary stem was used (Figs 7 to 9).

Between 1972 and 1978 combinations of these materials were used in an attempt to develop a standard design. Since 1978 we have used a TAl prosthesis joined

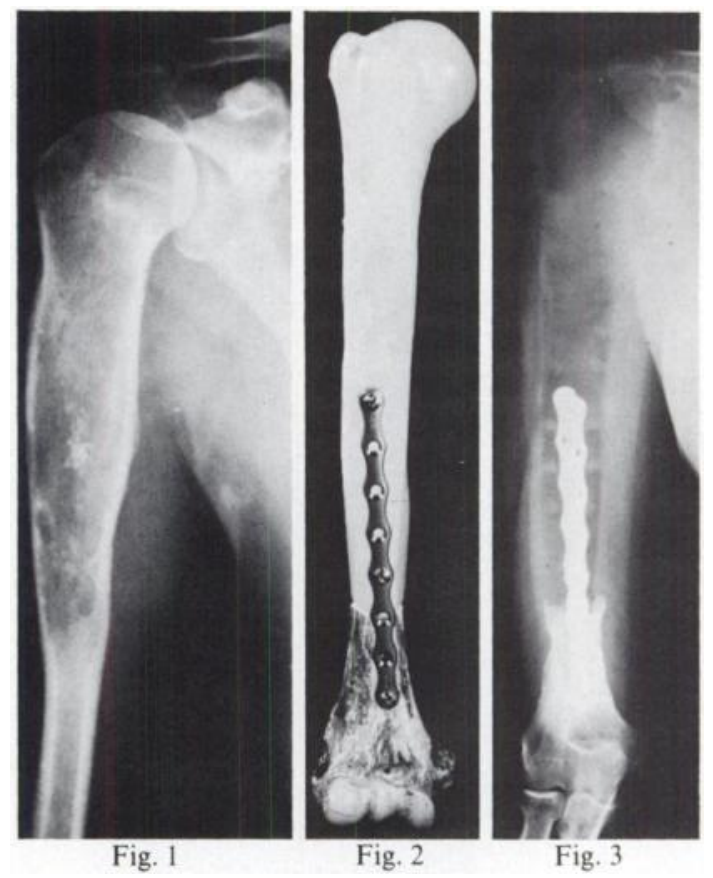

Figure 1 - Chondrosarcoma of the proximal humerus. Figure 2-The low-molecular-weight polyethylene prosthesis which was implanted in 1950 after resecting the tumour: there were holes in the prosthesis for reattachment of muscles and tendons. Figure 3 - Postoperative radiograph showing the prosthesis in situ.

to a shaped intramedullary stem either by shrink-fitting and rivetting or with nuts and bolts (Figs 10 to 12). Operative technique. After meticulous preparation, operation is carried out under antibiotic cover. The humerus is exposed through an anterolateral approach (Henry 1973) and the biopsy scar excised en bloc. The level of resection is identified (both clinically and radiologically) 


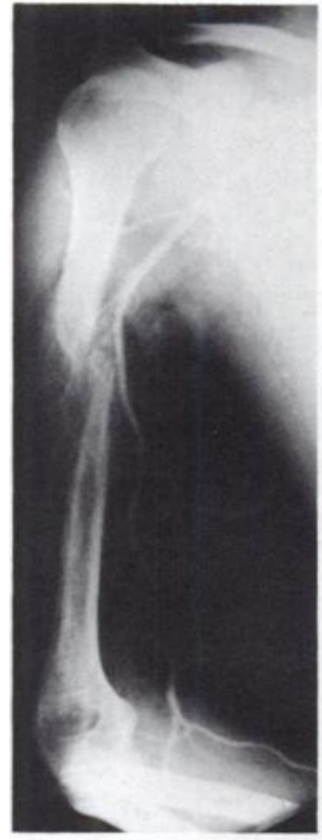

Fig. 4

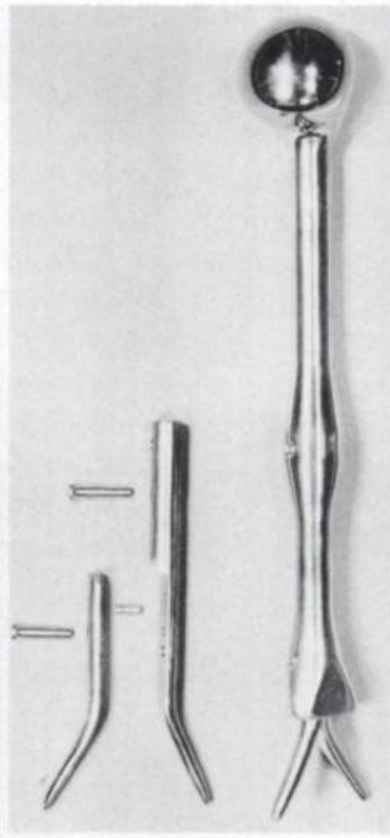

Fig. 5

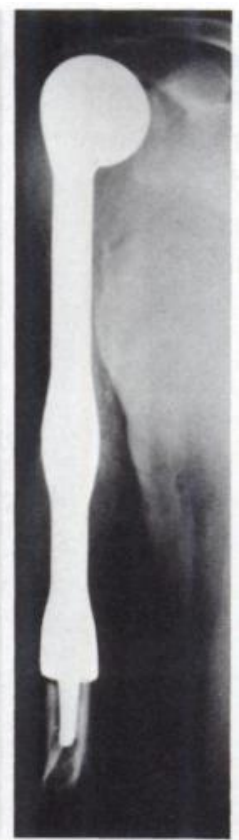

Fig. 6

In 1964 a patient with massive osteolysis (Fig. 4) was treated by insertion of a Titanium 160 prosthesis with divergent "fishtail" prongs (Figs 5 and 6).

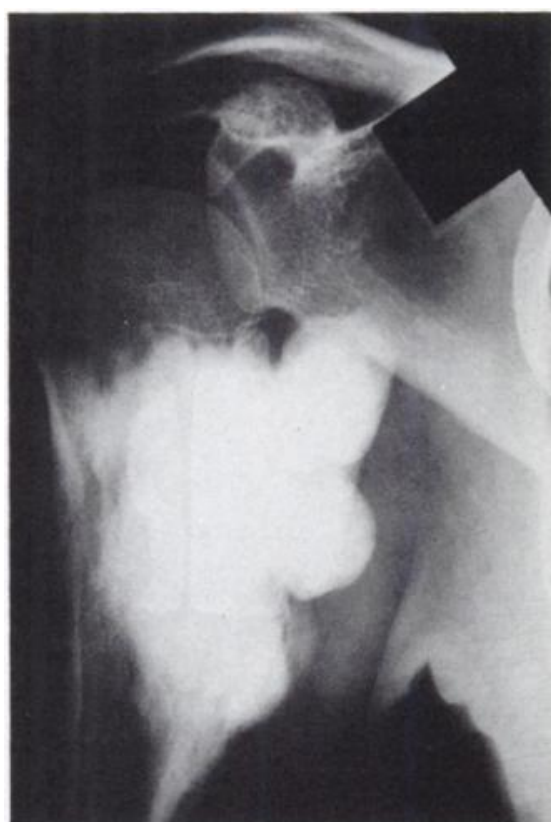

Fig. 7

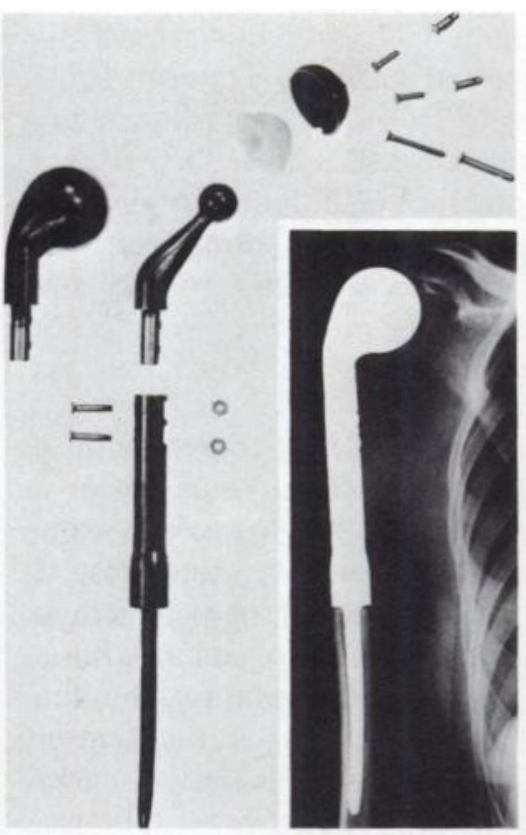

Fig. 8

Fig. 9

This parosteal sarcoma (Fig. 7) was thought suitable for total endoprosthetic replacement (Fig. 8), but for technical reasons only a hemiarthroplasty was performed (Fig. 9). 
and marked; it should be at least $5 \mathrm{~cm}$ below the lowest extent of a tumour. Another superficial mark is made on the humerus (distal to the line of resection) and corresponds to a similar orientation mark on the prosthesis itself. In order to articulate with the glenoid, the humeral head must face slightly backwards. The humerus is transected and the proximal portion containing the tumour removed by retrograde dissection, maintaining an unbroken layer of normal muscle around the specimen. On no account should the dissection be subperiosteal. patients died, two of metastases from highly malignant tumours but without local recurrence, and three from unrelated causes. Tumour recurred locally in two patients. One had an extensive recurrent chondrosarcoma and, having refused amputation, was offered prosthetic replacement; two years later, further recurrence made forequarter amputation inevitable, but the patient remains well after 14 years. The second patient had a secondary deposit from a hypernephroma which was resected, but 18 months later required a shoulder disarticulation for recurrence with wound breakdown.

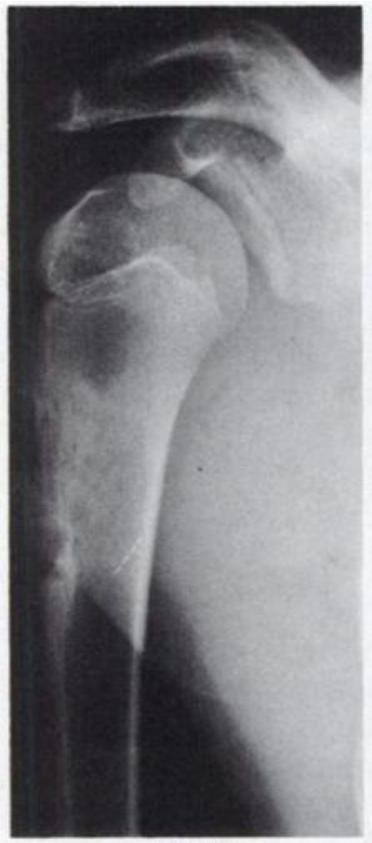

Fig. 10

This chondrosarcoma (Fig. 10) was treated by excision and replacement by the current Titanium 318 prosthesis (Figs 11 and 12).
The cavity of the humerus is prepared with a curette, or by serial reaming in increments of $0.5 \mathrm{~cm}$ if the cavity needs to be enlarged. A specimen of marrow from the site of resection is taken for biopsy, and a test-fit of the prosthesis carried out. Radiopaque polymethylmethacrylate cement (Simplex P, Howmedica, UK) is then injected from a hand-operated cement gun into the medullary cavity of the distal humerus and the stem of the prosthesis inserted, aligning the orientation marks correctly. No attempt is made to reattach the soft tissues to the prosthesis. The humeral head is reduced into the glenoid, the wound closed in layers over one or two suction drains and the arm immobilised in a spica bandage.

\section{RESULTS}

Follow-up ranged from one to 27 years with a mean of 11 years. Between seven and 23 years after operation, five
Each of the first five prostheses loosened, though only one required revision. The other 20 remained secure for an average of 5.5 years from implantation (range 1 to 19 years); the radiographs of six of these showed evidence of bone resorption at the junction with the prosthesis.

Intra-operative problems occurred on 18 occasions. Ten of these resulted from technical difficulties with the design and fitting of the prosthesis and occurred early in the period of follow-up. The other major difficulty was scarring from previous biopsies or resections (five patients) and radiotherapy (one patient); one patient had a pathological fracture.

There were 18 early postoperative complications. Six patients were pyrexial for up to one week, five had a superficial wound infection which settled rapidly on antibiotics, and there was transient swelling of the arm in three. Three developed radial nerve palsies, the mildest of which settled within two weeks, while the most severe 
remained virtually complete. One patient had a wound haematoma which discharged spontaneously. Eleven patients made an uncomplicated recovery and no prosthesis became infected.

Active flexion, extension and abduction at the shoulder were each reduced to less than $30^{\circ}$ in every patient. Passive movements were almost normal except for medial and lateral rotation (which were increased).

The head of the prosthesis was expected to subluxate under the coraco-acromial arch, and this occurred in 16 cases. In three others the humeral head dislocated above this level, and in four the position of the prosthetic humeral head was anatomically correct. The two patients who required amputation are not included.

The function and range of the elbow was normal in 12 of the 17 surviving limbs but reduced by an average of $20^{\circ}$ in five (range $5^{\circ}$ to $30^{\circ}$ ). In two of these the loss of movement was due to pre-existing rheumatoid arthritis. Wrist and hand function was also normal, except in these two rheumatoid patients.

\section{DISCUSSION}

The three patients with high-grade tumours all fared badly: two died from metastases within three years of operation. In patients with a poor prognosis, the aim of prosthetic replacement had been to control the local tumour without resorting to amputation; since in these patients the tumour did not recur, we do not regard these cases as failures. In the third patient with a secondary deposit from an isolated hypernephroma, shoulder disarticulation for local recurrence and wound infection was required; in this case the aim of surgery was not realised. The three other deaths in the series were unrelated either to the original tumour or to the operation.

Deep infection did not occur. Our results compare favourably with those of Campanacci et al. (1975) who reported a deep infection rate of $16 \%$ in their first series and $8 \%$ in their second (1982), as well as with Mankin's (1983) results of $7 \%$.

No intramedullary stem has loosened in the last 20 years nor has any loosening been reported by the doctors of those patients living abroad. Since titanium has been used as the implant material, there have been no fractures of the prosthesis. The combination of limited active movement and free passive movement at the shoulder virtually abolishes rotational shear forces at the bone-cement-prosthesis interfaces, while a long intramedullary stem spreads the bending load applied across the upper arm. Campanacci et al., who also employed a prosthesis with an intramedullary stem, reported no cases of loosening or fracture (Campanacci et al. 1982), while Salzer and his colleagues (1979) have had two cases of loosening with their prosthesis which is fixed to the distal humerus by means of a conical sleeve.

Muscles and tendons were not reattached to the prosthesis except on two occasions; one of these patients needed re-exploration and the tendons were found to have pulled out. In cases of malignancy, considerable portions of both the rotator cuff and deltoid muscle have been resected in order to achieve an adequate clearance, making reattachment impossible. As a result, although an excellent range of passive movement is retained, active movement is limited and seldom exceeds $30^{\circ}$ in any direction. Passive rotation is increased and may be useful. These findings are independent of the type of prosthesis used (Salzer et al. 1979; Campanacci et al. 1982). Muscles and tendons can be reattached to allografts and autografts, and this results in better active function (Mankin et al. 1983).

In some cases, where biopsy of the tumour had been carried out before orthopaedic referral, the site of the biopsy incision made operation problematic; scarring from multiple biopsies, radiotherapy or a pathological fracture undoubtedly makes the definitive operation more difficult, although we have no clear evidence that it influences the outcome.

Postoperative complications occurred frequently but were mostly minor. The radial nerve is clearly at risk, not only during dissection but also from traction once the proximal part of the humerus has been removed.

Conclusions. As a result of our experience, we have defined a set of criteria which we recommend when prosthetic replacement of the proximal humerus is being considered in cases of trauma and benign or low-grade tumour; we cannot recommend criteria for tumours of high-grade malignancy since our numbers are insufficient.

Prosthetic replacement should be considered in traumatic or benign lesions when destruction of the proximal half of the humerus is so severe that reconstruction by conventional means is impossible and replacement is the only alternative to a flail limb or amputation.

For tumours of low-grade malignancy we suggest that prosthetic replacement should be considered only if the following criteria are satisfied:

1. The tumour should be of low histological grade (Enneking G1).

2. It should be intraperiosteal or with limited extraperiosteal spread, and there should be no evidence of metastases (Enneking T1; Enneking, Spanier and Goodman 1980).

3. It should be confined to the upper humeral shaft, with sufficient bone in the lower half for satisfactory mechanical fixation. If the tumour is larger, total humeral replacement should be considered.

4. Previous local surgery has been kept to a minimum.

5. Complete macroscopic excision of the tumour is possible; if not, amputation should be performed.

6. The alternatives are extensive reconstruction, wide excision resulting in a flail limb, or amputation.

7. Pre-operative consent for amputation has been obtained in case resection proves impossible. 
Provided that these criteria are satisfied, the custom-made prosthesis is meticulously implanted, and the patient is prepared to accept limited active shoulder function, then prosthetic replacement of the proximal humerus is a safe and reliable method of treating destructive lesions of the upper humerus.

We thank Dr K. W. J. Wright, Mr H. R. Child and Mr R. H. Ansell, who were largely responsible for the design and manufacture of the prostheses; Ann Somes and Joan Woods for their help in the maintenance and retrieval of records; and Mrs Uta Boundy and Mr J. Collins of the photographic departments of the Royal National Orthopaedic Hospital for the illustrations. We also thank Mr J. I. L. Bayley, Professor G. Bentley, Mr J. A. Cholmeley and Mr H. B. S. Kemp who kindly allowed us to include their patients in this study.

\section{REFERENCES}

Albee FH. Restoration of shoulder function in cases of loss of head and upper portion of humerus. Surg Gynecol Obstet 1921;32:1-19.

Burrows HJ, Wilson JN, Scales JT. Excision of tumours of humerus and femur, with restoration by internal prostheses. $J$ Bone Joint Surg $[\mathrm{Br}]$ 1975;57-B:148-59.

Campanacei M, Guilino G, Olmi R, et al. Resezione-endoprotesi dell'omero prossimale (indicazioni e revisione di 37 casi). Chir Organi Mov 1975;62:465-9. (Eng. Abstr.)

Campanacei M, Cervellati C, Gherlinzoni F, Capanna R. Endoprosthesis of the humerus: description of a new model and its application. Ital J Orthop Traumatol 1982;8:59-65.

Clark K. A case of replacement of the upper end of the humerus by a fibular graft reviewed after twenty-nine years. J Bone Joint Surg $[\mathrm{Br}]$ 1959;41-B:365-8.

Doppelt SH, Tomford WW, Lucas AD, Mankin HJ. Operational and financial aspects of a hospital bone bank. J Bone Joint Surg [Am] $1981 ; 63-A: 1472-81$.

Enneking WF, Eady JL, Burchardt H. Autogenous cortical bone grafts in the reconstruction of segmental skeletal defects. J Bone Joint Surg [Am] 1980;62-A:1039-58.

Enneking WF, Spanier SS, Goodman MA. A system for the surgical staging of musculoskeletal sarcoma. Clin Orthop 1980;153:106-20.

Enneking WF. Musculoskeletal tumor surgery. New York: Churchill Livingstone, 1983

Gross A, McKee N, Farine I, Czitrom A, Langer F. Reconstruction of skeletal defects following en-bloc excision of bone tumors. In: Uhthoff HK, Stahl E, eds. Current concepts of diagnosis and treatment of bone and soft tissue tumours. Berlin, etc: SpringerVerlag, 1984:163-74.

Henry AK. Extensile exposure. 2nd ed. Edinburgh, etc: Churchill Livingstone, 1973.
Imbriglia JE, Neer CS, Dick HM. Resection of the proximal one-half of the humerus in a child for chondrosarcoma: preservation of function using a fibular graft and Neer prosthesis. J Bone Joint Surg [Am] 1978;60-A:262-4.

Lettin AWF. Fibular replacement of the upper humerus after segmental resection for chondrosarcoma. Proc R Soc Med 1964;57:90-3.

Lugli T. Artificial shoulder joint by Pean (1893): the facts of an exceptional intervention and the prosthetic method. Clin Orthop $1978 ; 133: 215-8$

Mankin HJ. Complications of allograft surgery. In: Friedlaender GE, Mankin HJ, Sell KW, eds. Osteochondral allografts: biology, banking and clinical applications. Boston, etc: Little, Brown \& Co, 1983:259-74.

Mankin HJ, Doppelt S, Tomford W. Clinical experience with allograft implantation: the first ten years. Clin Orthop 1983;174:69-86.

Miligram JW, Riley LH Jr. Haemangioendothelioma of the proximal part of the humerus: a case report. J Bone Joint Surg [Am] 1972;54-A:1543-47.

Ottolenghi CE. Massive osteo and osteo-articular bone grafts: technic and results of 62 cases. Clin Orthop 1972;87:156-64.

Packard AG Jr. Prosthetic replacement of the proximal half of the humerus. Clin Orthop 1973;93:250-2.

Péan M. Des moyens prothétiques destinés à obtenir la réparation de parties osseuses. Gazette des Hopitaux 1984;32:289-92.

Parrish FF. Allograft replacement of all or part of the end of a long bone following excision of a tumour: report of twenty-one cases. J Bone Joint Surg [Am] 1973;55-A:1-22.

Poirier H. Massive osteolysis of the humerus treated by massive resection and prosthetic replacement. J Bone Joint Surg $[\mathrm{Br}]$ $1968 ; 50-\mathrm{B}: 158-60$.

Roveing T. Ein Fall von freier Knochentransplantation zum Ersatz der zwei oberen Drittel des Oberarmes mit Hilfe der Fibula des Patienten. In: Garré K, König F, Richter E, eds. Zentralblatt für Chirurgie. Leipzig: Verlag von Johann Ambrosius Barth, 1910:870.

Salzer M, Knahr K, Locke $H$, et al. A bioceramic endoprosthesis for the replacement of the proximal humerus. Arch Orthop Trauma Surg 1979;93:169-84.

Schaufiler R McE. Transplant of the upper extremity of the fibula to replace the upper extremity of the humerus. J Bone Joint Surg $1926 ; 8: 723-6$.

Smith WS, Simon MA. Segmental resection for chondrosarcoma. $J$ Bone Joint Surg [Am] 1975;57-A:1097-103.

Volkor M. Allotransplantation of joints. J Bone Joint Surg [Br] 1970;52-B:49-53.

Weiland AJ, Moore JR, Daniel RK. Vascularized bone autografts: experience with 41 cases. Clin Orthop 1983;174:87-95.

Wilson PD, Lance EM. Surgical reconstruction of the skeleton following segmental resection for bone tumors. J Bone Joint Surg [Am] 1965;47-A:1629-56.

Yoshimoto S, Kaneso H, Tatematsa M. Total prosthetic replacement of a humerus for chronic osteomyelitis with a pathological fracture: report of a case. J Bone Joint Surg [Br] 1977;59-B:360-2. 